\title{
REAJUSTE POR SINISTRALIDADE EM CONTRATOS COLETIVOS EMPRESARIAIS DE ASSISTÊNCIA À SAÚDE - INTERPRETAÇÃO SEGUNDO OS PRINCÍPIOS CONSTITUCIONAIS DO DIREITO À SAÚDE E ARTIGOS $1^{\circ}$ E 170 DA CONSTITUIÇÃO FEDERAL DE 1988
}

Clause for readjustment related to increasing accidents in group health insurance contracts for businesses - Interpretation according to the constitutional principles on the right to health and to the articles 1 and 170 of the Brazilian 1988 Federal Constitution

Maria Eugênia Ferraz do Amaral Bodra*

\section{RESUMO}

Em um cenário em que se verifica a enorme dificuldade de estruturação e consolidação do Sistema Único de Saúde e de seus princípios diretivos, bem como a crescente importância do setor de saúde suplementar, este trabalho tem como finalidade refletir sobre a forma de interpretação dos conflitos derivados do contrato coletivo empresarial de assistência à saúde, já que este é um dos mais importantes instrumentos do setor de saúde suplementar da atualidade. Inicialmente são apresentadas as principais diferenças entre os contratos individuais e os contratos empresariais de assistência à saúde, em especial no tocante aos reajustes e à rescisão contratual. Em seguida, conclui-se que a divergência na interpretação dos casos do Superior Tribunal de Justiça aqui selecionados baseia-se no entendimento de cada Ministro sobre o enquadramento do contrato ou no ramo do direito empresarial ou no ramo do direito do consumidor, o que leva a consequências antagônicas em cada uma das duas hipóteses. Posteriormente, destaca-se a construção do direito social à saúde no âmbito nacional e internacional, seus princípios e a sua inter-relação com o setor da Saúde Suplementar, sugerindo a aplicação dessa principiologia como um todo

\footnotetext{
* Mestre em Saúde Global e Instituições Internacionais, Georgetown University (Washington) e Graduate Institute (Genebra); Mestre em Direito Comercial, Pontifícia Universidade Católica de São Paulo; Especialista em Direito Sanitário, Faculdade de Saúde Pública, Universidade de São Paulo. Advogada. São Paulo/SP - Brasil. E-mail: eugenia@amaralbodra.com.br
}

Artigo recebido em: 21/09/2012. Revisado em: 07/02/2013. Aprovado em: 14/02/2013. 
à interpretação do contrato em comento. Também são analisados os princípios previstos nos artigos $1^{\circ}$ e 170 da Constituição Federal de 1988, para demonstrar que, mesmo em contratos estritamente empresariais, o princípio da liberdade com solidariedade, que dá lastro à teoria do equilíbrio contratual com base na boa-fé objetiva, é que deve ser utilizado.

Palavras-chave: Contrato Coletivo Empresarial de Saúde; Direito à Saúde; Equilíbrio Contratual; Reajuste por Sinistralidade; Rescisão Contratual.

\begin{abstract}
In a scenario in which, on one hand, the organization and consolidation of the Brazilian National Public Health System and its guiding principles is of enormous difficulty and, on the other hand, the private health care system has acquired growing importance, this study aims to comprehend the interpretation on conflicts related to the group health insurance contracts for businesses, since this is one of the most important instruments of the private health care system nowadays. Initially, the explanation on the main differences between individual contracts and group health insurance contracts for business is presented, especially with regard to the readjustment clause related to increasing accidents and the termination of this contract. Then, it is concluded that the differing interpretation adopted in the Brazilian Superior Court cases here identified depends on the legal approach used by each judge, either the corporate law or the consumer law, which leads to antagonistic effects in each one of the two. After, the theory on the right to health is presented, considering its national and international approach, its principles and its interrelationship with the health insurance sector, with the aim to suggest that the interpretation of the contract in analysis should be submitted to these principles. The principles laid down in articles 1 and 170 of the Brazilian 1988 Constitution are also analyzed to demonstrate that even in strictly business contracts, the principle of freedom with solidarity which sustains the theory on contractual balance based on objective good faith, is the one that should be used.
\end{abstract}

Keywords: Adjustment for Claims; Contract Termination; Contractual Balance; Group Health Insurance Contracts for Businesses; Right to Health.

\title{
Introdução
}

A reforma sanitária brasileira, ${ }^{(1)}$ iniciada na década de 1970 e acolhida pela Constituição Federal de 1988 (CF/88), vem sofrendo nos últimos 25 anos

\footnotetext{
PAIM, Jairnilson Silva. Reforma sanitária brasileira: contribuição para compreensão e crítica Salvador: Edufba; Rio de Janeiro: Ed. Fiocruz, 2008. p. 26-27: "No caso do Brasil, surgiu em meados da década de 70, um movimento postulando a democratização da saúde, justamente num período no qual novos sujeitos sociais emergiram nas lutas contra a ditadura. Estudantes, professores universitários, setores populares e entidades de profissionais de saúde passaram a defender mudanças na saúde, culminando com a criação do Centro Brasileiro de Estudos de Saúde (CEBES) em 1976 (FLEURY, 1997). A conquista da democracia em 1985 possibilitou a realização da $8^{a}$ Conferência Nacional de Saúde no ano seguinte. Nesse evento, reafirmou-se o reconhecimento
} 
decisivas derrotas na sua implementação, ${ }^{(2)}$ especialmente no tocante à concretização dos princípios e diretrizes do Sistema Universal de Saúde (SUS) que propõem a realização de um sistema de saúde público universal, integral e equânime. Desde a década de 1990, verifica-se, de um lado, a ausência de uma força política interna, no Brasil, que defenda o financiamento adequado para a estruturação do SUS, e, de outro lado, uma crescente força econômica que passa a influenciar governo e sociedade, elegendo e determinando prioridades outras no setor de saúde, ${ }^{(3)}$ que estão longe de coincidir com os princípios do SUS.

da saúde como um direito de todos e dever do Estado, recomendando-se a organização de um Sistema Único de Saúde (SUS) descentralizado (com atribuições específicas para a União, estados e municípios) e democrático (garantindo a participação social na formulação das políticas de saúde, no acompanhamento e na avaliação). A partir dessa Conferência, a sociedade brasileira passou a dispor de um corpo doutrinário e de um conjunto de proposições políticas voltados para a saúde que apontavam para a democratização da vida social e para uma Reforma Democrática do Estado. E é justamente esse processo de democratização da saúde que naquela época cunhou o nome de Reforma Sanitária, concebida nos seguintes termos: 'Discutir a REFORMA SANITÁRIA nos seus aspectos conceituais, ideológicos, políticos e institucionais é, atualmente, tarefa fundamental de todos aqueles que, em diferentes países como o Brasil, Itália, Bolívia, Espanha, Portugal etc. estão comprometidos com a democratização das estruturas políticas e a melhoria da qualidade de vida dos cidadãos. Esta tarefa mais que fundamental, torna-se imprescindível para nós que buscamos, nas lutas pela Reforma Sanitária, construir as bases do socialismo democrático que almejamos para o Brasil (AROUCA, 1989b)'..".

2 Gasta-se pouco com saúde pública no Brasil. Enquanto a Alemanha utiliza 10,6\% do PIB, ou US\$ 3.465 per capita (dos quais 76,9\% são gastos públicos), o Brasil gasta apenas $7,5 \%$ do PIB, ou US\$ 679 dólares per capita (dos quais apenas 47,9\% são gastos públicos) (OMS-2009). Conforme a OPAS, $6 \%$ do PIB são o mínimo que os governos deveriam investir em saúde. A Constituição Federal de 1988 criou o conceito de seguridade social (previdência, saúde e assistência social) com orçamento próprio e fontes exclusivas de financiamento. São fontes da União, as contribuições sociais dos empregadores (incidentes sobre a folha de salários, sobre a receita ou o faturamento e sobre o lucro), as contribuições sociais dos trabalhadores e $50 \%$ da receita de concursos e prognósticos (loteria). Dos recursos do Orçamento da Seguridade Social, $30 \%$ deveriam ser destinados ao Sistema único de Saúde. Há ainda as receitas provenientes dos Tesouros Estaduais e Municipais. Ocorre que nenhum governo posterior à Constituição de 1988 cumpriu essas normas. Desde 1988 ocorreram sucessivos embates que, um a um, vêm prejudicando o financiamento do SUS. Ver MENDES, Áquilas; MARQUES, Rosa Maria. Crônica de uma crise anunciada: o financiamento do SUS sob a dominância do capital financeiro. Disponível em: <http://www.apufpr. org.br/artigos/trabalho_cronica_de_uma_crise_anunciada_financiamento_sus_aquilas_mendes_e. pdf>. Acesso em: 22 maio 2012.

${ }^{3}$ As complexas relações entre o público e o privado na saúde são exploradas com propriedade nos seguintes textos: BAHIA, Ligia. A unificação do sistema público e a expansão do segmento suplementar: as contradições entre o SUS universal e as transferências de recursos públicos para os planos e seguros privados de saúde. Ciência \& Saúde Coletiva, Rio de Janeiro, v. 13, n. 5, p. 1398-1408, set./out. 2008; OCKÉ-REIS, Carlos Octávio. O mercado de planos de saúde: o problema vira solução. Ciência \& Saúde Coletiva, Rio de Janeiro, v. 13, n. 5, p. 1398-1400, set./ out. 2008; MENICUCCI, Telma Maria Gonçalves, Relação público-privada no sistema de saúde brasileiro: opacidade cognitiva e analítica, Ciência \& Saúde Coletiva, Rio de Janeiro, v. 13, n. 5, p. 1400-1403, set./out. 2008 e; SILVA, Silvio Fernades da. Interfaces entre a Gestão do SUS e a regulação de planos privados de saúde. Ciência \& Saúde Coletiva, Rio de Janeiro, v. 13, n. 5, p. 1400-1403, set./out. 2008. 
De fato, o crescimento do sistema suplementar de saúde, especialmente através do contrato coletivo empresarial de assistência à saúde, retoma, em grande parte, a lógica do sistema anterior à reforma sanitária que privilegiava o fornecimento de assistência médica apenas aos detentores de emprego formal. ${ }^{(4)}$

Nesse contexto, cabe refletir sobre a interpretação jurídica que se deve dar ao contrato coletivo empresarial de assistência à saúde, considerando as molduras legal e constitucional, nas quais está inserido.

Segundo levantamento da Agência Nacional de Saúde Suplementar (ANS) feito em setembro de 2011, o número total de brasileiros beneficiários de planos de saúde é de 47.008.888 pessoas, dos quais 29.163.296 realizaram contratação por meio de planos coletivos empresariais, 6.951 .510 por planos coletivos por adesão, 37.876 por planos coletivos não identificados e 9.656 .863 por meio de planos individuais. ${ }^{(5)}$

Neste trabalho, será analisado somente o contrato coletivo empresarial de assistência à saúde, que em geral tem seus custos/prêmios patrocinados no todo ou em sua maior parte pela empresa empregadora. Veja-se que os contratos coletivos empresariais já representam, atualmente, $62 \%$ dos beneficiários do mercado de saúde suplementar no Brasil.

O contrato coletivo empresarial é aquele que oferece cobertura à população delimitada e vinculada à pessoa jurídica por relação empregatícia ou estatutária, conforme Resolução Normativa - RN no 195, artigo $5^{\circ(6)}$ da ANS. Para o direito do consumidor, cinco características principais diferenciam o contrato coletivo empresarial do contrato individual: ${ }^{(7)}$

\footnotetext{
${ }^{4}$ Sobre o processo histórico da assistência privada à saúde no Brasil e sua vinculação ao emprego formal, vale conferir COHN, Amélia; NUNES, Edison; JACOBI, Pedro R; KARSCH, Ursula S. $A$ saúde como direito e como serviço. 6. ed. São Paulo: Cortez, 2010.

${ }^{5}$ Fonte: ANS. Disponível em: <http://www.ans.gov.br/index.php/materiais-para-pesquisas/perfil-dosetor/dados-e-indicadores-do-setor>. Acesso em: 23 dez. 2011.

${ }^{6}$ Art. $5^{\circ}$. "Plano privado de assistência à saúde coletivo empresarial é aquele que oferece cobertura da atenção prestada à população delimitada e vinculada à pessoa jurídica por relação empregatícia ou estatutária (...)." Diferentemente, o contrato coletivo por adesão oferece cobertura por pessoa jurídica para uma massa delimitada de consumidores, sendo a adesão espontânea e opcional do funcionário, associado ou sindicalizado, conforme definição do artigo $9^{\circ}$ desta mesma $\mathrm{RN} \mathrm{n}^{\circ} 195$ da ANS. Apesar de apresentarem questões bastante semelhantes aos contratos empresariais, distinguem-se destes por não serem patrocinados por uma empresa empregadora. BRASIL. AGÊNCIA NACIONAL DE SAÚDE SUPLEMENTAR. Resolução Normativa - RN nº 195, de 14 de julho de 2009. "Dispõe sobre a classificação e características dos planos privados de assistência à saúde, regulamenta a sua contratação, institui a orientação para contratação de planos privados de assistência à saúde e dá outras providências". Disponível em: <http://www.ans.gov.br/index2. php?option=com_legislacao\&view=legislacao\&task=TextoLei\&format=raw\&id=1458>. Acesso em: 19 ago. 2013.

7 No mais, aplicam-se aos contratos coletivos, todas as demais disposições aplicáveis aos contratos individuais, entre elas o rol de coberturas mínimo obrigatório, as regras sobre segmentação e cobertura, entre outras.
} 
1) a contratação é feita através de um intermediário ou pessoa jurídica, que no caso do contrato empresarial é o próprio empregador ou empresa estipulante, e não livremente por qualquer pessoa física;

2) os reajustes dos prêmios/mensalidades não são diretamente regulados pela ANS. ${ }^{(8)} \mathrm{Na}$ prática, isso significa que, além do reajuste por faixa etária, é possível aplicar ao contrato coletivo empresarial também, a cada doze meses, um reajuste decorrente da variação de custos, comumente conhecido como reajuste por sinistralidade, que, diversamente do percentual fixo determinado pela ANS aos contratos individuais, é livremente determinado pela operadora com base no valor dos gastos com o grupo segurado;

3) o contrato coletivo empresarial pode ser rescindido por ambas as partes, bastando o envio de uma notificação prévia com antecedência mínima de 60 dias, ${ }^{\left({ }^{9}\right)}$

4) o funcionário aposentado e/ou demitido sem justa causa da empresa estipulante deve preencher determinados requisitos para se manter como beneficiário do plano empresarial após a aposentadoria e/ou demissão;(10)

5) nos planos coletivos empresariais com número de participantes igual ou superior a trinta beneficiários, não poderá ser exigido o cumprimento de prazos de carência nem poderá haver cláusula de agravo ou de cobertura parcial temporária, nos casos de doenças ou lesões preexistentes, nos termos dos artigos $6^{\circ}$ e $7^{\circ}$ da RN n 195 da ANS.

Verifica-se que nos contratos coletivos empresariais, diversamente dos contratos individuais, a ANS confere uma grande liberdade às partes para a negociação de dois de seus elementos fundamentais: os reajustes dos prêmios/mensalidades e a rescisão contratual.

A RN no 195 da ANS, em seus artigos 19 a 22, limitou os reajustes dos contratos coletivos apenas nos seguintes aspectos: (i) restringiu a aplicação dos reajustes à periodicidade mínima de 12 meses, com exceção do reajuste por faixa etária; (ii) proibiu a aplicação de reajustes diferenciados dentro de um mesmo plano; e (iii) proibiu a distinção quanto ao valor da contraprestação pecuniária entre os beneficiários que vierem a ser incluídos no contrato e os a ele já vinculados. ${ }^{(11)}$

\footnotetext{
${ }^{8}$ Conforme artigo 19 da RN no 195 da ANS. Ver também PLANOS de Saúde: nove anos após a Lei 9.656/98. As falhas da regulamentação, A omissão da Agência Nacional de Saúde (ANS), O comportamento do mercado. São Paulo: Conselho Regional de Medicina do Estado de São Paulo; Instituto de Defesa do Consumidor, 2007.

9 Conforme artigo 17. BRASIL. AGÊNCIA NACIONAL DE SAÚDE SUPLEMENTAR. Resolução Normativa - RN n ${ }^{\circ} 195$, cit.

${ }^{10}$ De acordo com os artigos 30 e 31 da Lei no 9.656/98. BRASIL. Lei $n^{\circ} 9.656$, de 3 de junho de 1998. "Dispõe sobre os planos e seguros privados de assistência à saúde". Disponível em: <http://www. planalto.gov.br/ccivil_03/leis/L9656compilado.htm>. Acesso em: 19 ago. 2013.

${ }^{11}$ BRASIL. AGÊNCIA NACIONAL DE SAÚDE SUPLEMENTAR. Resolução Normativa - RN n 195, cit.
} 
E em 24 de outubro de 2012, a ANS editou a Resolução Normativa - RN n $309,{ }^{(12)}$ através da qual determinou o agrupamento de contratos coletivos empresariais e por adesão, firmados após $1^{\circ}$ de janeiro de 1999, ou adaptados à Lei $n^{\circ} 9.656 / 98$, para fins de cálculo e aplicação de reajuste, com o fim, justamente, de diluir o risco de contratos coletivos com 30 ou menos beneficiários em um grupo maior de beneficiários.

Portanto, consoante as regras ditadas pela Lei $n^{\circ} 9.656 / 98$ e pela ANS, hoje o mercado dispõe de grande margem de liberdade para aplicar os reajustes ao contrato coletivo empresarial de que se cuida, desde que obedecidas as regras apresentadas.

Dentre os reajustes aplicados ao citado contrato coletivo, destaca-se o chamado reajuste por sinistralidade, que é aplicado somente ao contrato coletivo e sempre que a operadora sentir a necessidade de ajustar seus prêmios ou receitas, com base nas despesas do grupo segurado. Diversamente dos reajustes por faixa etária e de atualização anual que são também aplicados aos contratos individuais - mas que, nos contratos individuais têm seus índices diretamente fixados pela ANS -, o reajuste por sinistralidade é aplicado apenas ao contrato coletivo.

Diante da importância crescente dos contratos coletivos empresariais e da grande liberdade de negociação conferida pela ANS às operadoras de saúde e às empresas estipulantes que negociam este contrato em favor de seus funcionários,

\footnotetext{
${ }^{12}$ Art. $3^{\circ}$. "É obrigatório às operadoras de planos privados de assistência à saúde formar um agrupamento com todos os seus contratos coletivos com menos de 30 (trinta) beneficiários para o cálculo do percentual de reajuste que será aplicado a esse agrupamento. $\S 1^{\circ} \mathrm{E}$ facultado às operadoras de planos privados de assistência à saúde agregar contratos coletivos com 30 (trinta) ou mais beneficiários ao agrupamento de contratos descrito no caput, desde que estabeleça expressamente em cláusula contratual qual será a quantidade de beneficiários a ser considerada para a formação do agrupamento. $\S 2^{\circ}$ Qualquer que seja a quantidade de beneficiários estabelecida pela operadora de planos privados de assistência à saúde para formar o agrupamento de contratos, deverão ser observadas as regras estabelecidas nesta Resolução, e sua alteração somente poderá ocorrer mediante aditamento dos contratos coletivos". Art. $4^{\circ}$. "Ressalvada a hipótese prevista no artigo $5^{\circ}$, a operadora, após a apuração da quantidade de beneficiários prevista artigo $6^{\circ}$, calculará um único percentual de reajuste, que deverá ser aplicado para todo o agrupamento dos seus contratos coletivos, independentemente do plano contratado". Art. $5^{\circ}$. "O agrupamento de contratos coletivos de que trata o artigo $3^{\circ}$ poderá ser desmembrado em até 3 (três) subagrupamentos, separados pelo tipo de cobertura, que é definido de acordo com a segmentação assistencial do plano ao qual o contrato está vinculado, da seguinte forma: I - sem internação: engloba os planos de segmentação assistencial 'ambulatorial' e 'ambulatorial + odontológico'; II - internação sem obstetrícia: engloba os planos que possuam segmentação assistencial 'hospitalar sem obstetrícia', 'hospitalar sem obstetrícia + odontológico', 'ambulatorial + hospitalar sem obstetrícia' e 'ambulatorial + hospitalar sem obstetrícia + odontológico'; e III - internação com obstetrícia: engloba os planos que possuam segmentação assistencial 'hospitalar com obstetrícia', 'hospitalar com obstetrícia + odontológico', 'ambulatorial + hospitalar com obstetrícia', 'ambulatorial + hospitalar com obstetrícia + odontológico', e 'referência”'. BRASIL. AGÊNCIA NACIONAL DE SAÚDE SUPLEMENTAR. Resolução Normativa - RN n 309, de 24 de outubro de 2012. "Dispõe sobre o agrupamento de contratos coletivos de planos privados de assistência à saúde para fins de cálculo e aplicação de reajuste". Disponível em: <http://www.ans.gov. br/texto_lei.php?id=2282\%20 >. Acesso em: 19 ago. 2013.
} 
surge o interesse de identificar os principais conflitos existentes entre as partes e também os princípios e regras jurídicas que devem ser aplicados a esses conflitos.

O esforço na identificação desses conflitos e dos princípios e regras que os disciplinam será limitado, por razões práticas, à apreciação dos argumentos que o Superior Tribunal de Justiça (STJ) adota quando tais conflitos the são submetidos. Como o STJ é responsável pela decisão final, na via judicial, de questões infraconstitucionais que lhe são submetidas, os argumentos utilizados em seus acórdãos tendem a "realimentar" o sistema jurídico, ou seja, as novas discussões judiciais sobre os mesmos conflitos tendem a ser dominadas pelos argumentos definidos pelo STJ que, com o passar do tempo, tendem a ser incorporados à legislação. Antes da incorporação de tais argumentos pela legislação, é indispensável analisá-los, já que isso permitirá a elaboração de novas propostas capazes de enfrentar a complexidade de uma sociedade cada vez mais dependente do setor de saúde suplementar.

Nesses termos, optamos por analisar, primeiramente, os argumentos e princípios jurídicos utilizados pelos julgadores no Superior Tribunal de Justiça sobre (i) a liberdade de negociação do reajuste por sinistralidade nos contratos coletivos empresariais de assistência à saúde e, na medida em que este segundo argumento surgir, também sobre (ii) a rescisão contratual decorrente ou relacionada a esse reajuste. Os critérios de análise dos julgados selecionados são indicados a seguir.

\section{Casos pesquisados no STJ}

São muitos os julgados do STJ que tratam de cláusulas de reajuste em contratos de saúde suplementar. Nos dias 11 e 12 de janeiro de 2012, foi feita uma pesquisa livre no sítio do tribunal, através do link "jurisprudência", assinalando acórdãos e súmulas com os seguintes termos: 1) "Plano e saúde e reajuste": 67 acórdãos encontrados; e 2) "Seguro e saúde e reajuste": 12 acórdãos encontrados.

Em seguida, foi feita uma pesquisa assinalando acórdãos, súmulas e decisões monocráticas, com os seguintes termos: 1) "Plano e saúde e reajuste e adesão": quatro acórdãos e 25 decisões monocráticas encontrados; 2) "sinistralidade e reajuste e saúde e plano": dois acórdãos e 16 decisões monocráticas encontrados; 3) "Saúde e reajuste e seguro e empresarial": um acórdão e 34 decisões monocráticas encontrados; 4) "Saúde e reajuste e plano e empresarial": um acórdão e 37 decisões monocráticas encontrados; 5) "Seguro adj2 saúde e reajuste e \$empresa\$": cinco acórdãos e 50 decisões monocráticas encontrados; e 6) "seguro adj2 saúde e reajuste": sete acórdãos e 114 decisões monocráticas encontrados.

Após análise de todos esses julgados, foram identificados três julgados nos quais os ministros discutiram a aplicação do reajuste por sinistralidade em contratos empresariais. Vale esclarecer que foram selecionados apenas os casos nos quais foi possível identificar conjuntamente (i) a existência de um contrato entre empresas e (ii) a discussão sobre um reajuste que se refere a um aumento de gastos com 
sinistros, ou seja, um reajuste que não se confunde com aquele que busca repor a inflação do período, nem com aquele que se aplica em razão da alteração da faixa etária da população delimitada. Foram excluídos todos os casos nos quais não foi possível identificar, com segurança, o tipo de reajuste discutido e/ou que tratavam de contratos coletivos por adesão. Relembre-se que, apesar de estes últimos apresentarem questões bastante semelhantes aos contratos coletivos empresariais, distinguem-se destes por não serem patrocinados por uma empresa empregadora.

Os três julgados selecionados foram:

1. Recurso Especial (REsp) 1.102.848/SP, ${ }^{(13)}$ cujo acórdão foi publicado em 25 de outubro de 2010 e no qual foram proferidos três votos. Um pela ministra relatora Nancy Andrighi, outro pelo ministro Massami Uyeda (voto vencedor) e o terceiro pelo ministro Sidnei Beneti (que acompanhou o voto vencedor). Importante ressaltar que o voto de Nancy Andrighi teve 24 páginas e tratou de diversos aspectos do sistema de saúde suplementar no Brasil. Os desembargadores convocados Vasco Della Giustina (Tribunal de Justiça do Rio Grande do Sul) e Paulo Furtado (Tribunal de Justiça da Bahia) acompanharam o voto vencedor.

2. Agravo de Instrumento (AI) 1.328.171/SP, ${ }^{(14)}$ por decisão monocrática do ministro Luis Felipe Salomão, publicado em 6 de junho de 2011.

3. Agravo Regimental (AgRg) em Agravo de Instrumento 1.131.324/MG, ${ }^{(15)}$ cujo acórdão foi publicado em 3 de junho de 2009 e no qual o voto do ministro relator Sidnei Beneti foi acompanhado por Massami Uyeda e Nancy Andrighi e pelos desembargadores convocados Vasco Della Giustina e Paulo Furtado.

Optamos por deixar de apreciar o último julgado indicado, AgRg em Agravo de Instrumento $n^{\circ} 1.131 .324 / \mathrm{MG}$, visto que este foi decidido sem votos divergentes pelos mesmos ministros que julgaram o REsp 1.102.848/SP (o primeiro julgado indicado). Veja-se que o acórdão proferido no REsp 1.102.848/SP não só é posterior àquele proferido no AgRg 1.131.324/MG, como também parece demonstrar que os ministros estudaram a questão de modo mais profundo, ante a divergência de entendimentos ocorrida no julgamento do processo.

Portanto, serão analisados os argumentos lançados em quatro votos diferentes. Três deles emitidos no julgamento do REsp 1.102.848/SP e um emitido no julgamento do Al 1.328.171/SP.

\footnotetext{
${ }^{13}$ SUPERIORTRIBUNALDEJUSTIÇA. Recurso Especial(REsp) 1.102.848/SP.Disponívelem:<https:// ww2.stj.jus.br/revistaeletronica/ita.asp?registro=200802744932\&dt_publicacao=25/10/2010 >. Acesso em: 19 ago. 2013.

${ }^{14}$ SUPERIOR TRIBUNAL DE JUSTIÇA. Agravo de Instrumento (AI) 1.328.171/SP. Disponível em: $<\mathrm{http}: / /$ www.stj.jus.br/webstj/Processo/Justica/detalhe.asp?numreg=201001154309\&pv=01000000 0000\&tp $=51>$. Acesso em: 19 ago. 2013.

${ }^{15}$ SUPERIOR TRIBUNAL DE JUSTIÇA. Agravo Regimental (AgRg) em Agravo de Instrumento 1.131.324/MG. Disponível em: <http://www.stj.jus.br/webstj/Processo/Justica/detalhe.asp?numreg $=200802781130 \& p v=010000000000 \& t p=51>$. Acesso em: 19 ago. 2013
} 
Os quatro votos são díspares no que concerne ao reajuste e à rescisão contratual, decorrente ou relacionada ao reajuste. São discutidas questões como a aplicação do Código de Defesa do Consumidor (CDC), ${ }^{(16)}$ a natureza securitária do contrato em causa, o equilíbrio e a transparência contratual.

Para fins desta pesquisa serão relatados e comparados os principais fundamentos jurídicos que sustentam a posição atual dos quatro votos diferentes sobre o tema, com base em três grandes subtemas: (i) a natureza jurídica das relações entre as partes contratantes; (ii) a aplicação do CDC; e (iii) a validade e aplicabilidade das cláusulas de reajuste e de rescisão por sinistralidade.

Os votos serão analisados apenas no tocante aos argumentos relacionados às cláusulas de reajuste por sinistralidade e de rescisão contratual quando esta cláusula também for objeto de discussão. Serão totalmente desconsiderados quaisquer argumentos preliminares e/ou processuais que digam respeito ao trâmite ou ao conhecimento do recurso.

Por fim, cabe ressaltar que serão analisados apenas os argumentos contidos nos referidos julgados, visto que não foi possível confirmar ou examinar as bases fáticas ou as demais peças e decisões proferidas em cada um desses processos.

\section{Natureza jurídica das relações entre as partes contratantes}

Em voto proferido no REsp 1.102.848/SP, Massami Uyeda afirmou que a relação entre a empresa que estipula o seguro em benefício de seus funcionários e a seguradora é comercial, já que as empresas oferecem tais benefícios a seus funcionários para atrair bons profissionais.

O citado ministro reconhece que o contrato em análise é complexo porque os empregados podem aderir e pagar uma parte do plano/seguro e menciona que há responsabilidade da operadora de saúde perante os empregados. Ele não esclarece, contudo, de que forma tal responsabilidade deve ser efetivada, já que seu comentário sobre o tema resume-se ao trecho a seguir transcrito:(17) “(...) as reclamações dos empregados se dão, na linha de frente, com o próprio empregador, embora a prestadora tenha responsabilidades para com cada um dos empregados que aderiu ao seguro coletivo".

Esse voto de Massami Uyeda foi vencedor, já que foi acompanhado por Sidnei Beneti (que, mesmo assim, apresentou voto-vista adiante examinado) e pelos desembargadores convocados Vasco Della Giustina (Tribunal de Justiça do Rio Grande do Sul) Paulo Furtado (Tribunal de Justiça da Bahia).

\footnotetext{
${ }^{16}$ BRASIL. Lei $n^{\circ} 8.078$, de 11 de setembro de 1990. "Dispõe sobre a proteção do consumidor e dá outras providências". Disponível em: < http://www.planalto.gov.br/ccivil_03/leis/l8078.htm>. Acesso em: 19 ago. 2013.

${ }^{17}$ SUPERIOR TRIBUNAL DE JUSTIÇA. Recurso Especial (REsp) 1.102.848/SP, cit.
} 
Portanto, fica claro que o entendimento descrito é o de que há uma relação comercial entre operadora de saúde e empresa-estipulante, que rege de forma predominante esse contrato.

Acrescente-se que Sidnei Beneti, em seu voto-vista, concluiu que se teria um contrato cativo de longa duração, o que, na sua visão, impede a rescisão imotivada do contrato, mas não o reajuste por sinistralidade.

A relatora Nancy Andrighi, que proferiu voto vencido de 24 páginas no REsp 1.102.848/SP, ao tratar da natureza jurídica das relações entre os contratantes, citou diversos doutrinadores e concluiu que se trata de um acordo de caráter consumeirista, com base securitária, visto que se denotam os elementos do risco, do prêmio e do evento indenizável. Ao citar Cláudia Lima Marques, conclui tratar-se de nova modalidade de seguro que envolve um "fazer futuro muito mais complexo que a simples entrega de uma quantia monetária". ${ }^{(18)}$

Já o ministro Luis Felipe Salomão não se manifestou sobre a natureza jurídica desse contrato em suas razões de decidir no Al 1.328.171/SP.

\section{Aplicação do CDC}

No julgamento do REsp 1.102.848/SP, Massami Uyeda afirmou que o CDC não se aplica a esse tipo de contrato pelos seguintes motivos: ${ }^{(19)}$ (i) aplicar o CDC a contrato entre duas empresas em razão da diferença de porte econômico entre elas causa insegurança jurídica às relações comerciais e aos contratos, aumentando o custo dos serviços e produtos, o que prejudica o cidadão; (ii) a relação entre essas empresas não pode ser considerada de consumo apenas porque o objeto do contrato firmado entre elas é a prestação dos serviços de seguro-saúde; (iii) o empregador que oferece pacote de benefícios aos seus empregados pode, quando quiser, procurar outra operadora para fornecer tal serviço. Nesse ponto, o ministro explicou que(20) "a questão da rescisão do contrato não é objeto do recurso especial, mas a explanação serve para nos colocar frente à realidade de que não se trata de um caso onde se possa aplicar a hipossuficiência e, compulsoriamente, o Código de Defesa do Consumidor". Vale repetir que esse voto de Massami Uyeda foi vencedor.

Para a relatora Nancy Andrighi, que proferiu voto vencido no mesmo julgado, o CDC deve ser aplicado ao contrato coletivo empresarial. Defendeu ela que ${ }^{(21)}$

assim como os seguros em geral, os planos de saúde se submetem à Lei 8.078/90, pois as partes que participam do negócio se enquadram perfeitamente nos conceitos de consumidor e

\footnotetext{
${ }^{18}$ SUPERIOR TRIBUNAL DE JUSTIÇA. Recurso Especial (REsp) 1.102.848/SP, cit.

${ }^{19}$ Id. Ibid.

${ }^{20}$ Id. Ibid.

${ }^{21}$ Id. Ibid.
} 
fornecedor, tal qual previstos nos arts. $2^{\circ}$ e 3 do CDC: o conveniado ${ }^{(22)}$ se enquadra na definição de consumidor, usufruindo o serviço de assistência à saúde como destinatário final, e a operadora se reveste da condição de fornecedora, prestando esse serviço mediante remuneração.

A ministra também discorda da existência de liberdade de negociação entre empresa-estipulante e operadora, com base no seguinte argumento:(23)

Importante frisar, nesse ponto, haver quem sustente que os contratos coletivos de saúde não são de adesão, na medida em que suas cláusulas e condições seriam fixadas em conjunto pela operadora e pela pessoa jurídica contratante, com ampla margem de negociação, sem configurar a hipossuficiência de uma parte frente à outra. Há de se considerar, porém, que os planos coletivos estabelecem uma relação triangular, em que o beneficiário se mantém alheio à definição das cláusulas contratuais, limitando-se a anuir com o seu conteúdo por ocasião da formalização do seu vínculo empregatício, associativo ou sindical. Assim, sob a ótica do beneficiário, a contratação destes planos se dá sob o regime de adesão. Some-se a isso o fato de que boa parte dos planos coletivos é firmada por intermédio de pessoas jurídicas de pequeno e médio porte, situação que conserva a condição de hipossuficiência técnica e financeira frente às operadoras. Os planos coletivos de saúde, portanto, também se formalizam por adesão, visto que nessa modalidade de contratação os conveniados estão sujeitos a excessos equivalentes aos dos planos individuais, devendo se Ihes aplicar os mesmos princípios protetivos.

Por fim, Luis Felipe Salomão entendeu, no Al 1.328.171/SP, que deve ser aplicado o CDC ao caso, com base no Enunciado $469^{(24)}$ do STJ, que determina a aplicação do CDC aos contratos de plano de saúde.

\section{Validade e aplicabilidade das cláusulas de reajuste e de rescisão por sinistralidade}

Após afastar a aplicação do CDC no REsp 1.102.848/SP, o ministro Massami Uyeda explica que a legislação que rege os planos coletivos é diferente daquela que rege os planos individuais de saúde, justamente porque os contratos são feitos entre empresas e associações.

Aplicando então o Código Civil, o ministro defendeu que os cálculos atuariais e os reajustes por sinistralidade são necessários à manutenção do equilíbrio contratual, com base nos artigos 478 e 479 do Código Civil. Entendeu que as

\footnotetext{
${ }^{22}$ Conveniado parece ser então o empregado ou beneficiário do plano de saúde.

${ }^{23}$ SUPERIOR TRIBUNAL DE JUSTIÇA. Recurso Especial (REsp) 1.102.848/SP, cit.

${ }^{24}$ SUPERIOR TRIBUNAL DE JUSTIÇA. Agravo de Instrumento (AI) 1.328.171/SP, cit.
} 
duas empresas envolvidas na lide(25) "desenharam um seguro saúde e estabeleceram que, sempre que houvesse aumento da sinistralidade superior a $65 \%$ (...), haveria necessidade de se reequilibrar o plano". Concluiu que esse desenho tem por finalidade não tornar tais planos onerosos aos trabalhadores, cabendo ao empregador resolver o problema do aumento da sinistralidade, já que se refere ao seu pacote de benefícios, de forma que não cabe então transferir tais custos à operadora. Como dito, o voto de Massami Uyeda foi acompanhado por Sidnei Beneti e pelos desembargadores convocados Vasco Della Giustina e Paulo Furtado.

Portanto, na visão desses julgadores, seria válida a cláusula que estipula o reajuste por sinistralidade, visto que atenderia à necessidade de manutenção do equilíbrio contratual, com base nos artigos 478 e 479 do Código Civil. Em outro trecho do acórdão, ${ }^{(26)}$ Massami Uyeda mencionou também que o empregador tem a prerrogativa de rescindir o contrato a qualquer tempo, utilizando tal argumento para justificar que a seguradora ainda tem direitos a serem protegidos, de modo que não se pode aplicar o CDC. Depreende-se, dessa forma, que o referido ministro tende ${ }^{(27)}$ a concluir que essa relação é comercial e que a cláusula de rescisão contratual em caso de reajuste por sinistralidade seria legal.

Apesar de ter acompanhado Massami Uyeda no REsp 1.102.848/SP, Sidnei Beneti apresentou voto-vista no qual manifestou o entendimento de que há, no caso, duas teses centrais. Uma relativa à rescisão do contrato e outra relativa ao reajuste. Beneti sustentou que a seguradora não pode ter a faculdade potestativa de rescindir o contrato, pois tal outorga seria verdadeiro direito de $\mathrm{e}^{(28)}$

denúncia vazia sob o pretenso fundamento da elevação dos riscos, naturais e previsíveis que tem ela o dever de bem contratar - não podendo simplesmente invocar o próprio interesse em pagar menos do que o risco assumido, para da obrigação para com o contratante cativo de longa duração exonerar-se.

Beneti ressalvou, porém, situações excepcionais e motivadas, vale dizer, em denúncia cheia, sujeitas à controvertibilidade jurisdicional. Mas entendeu que o valor das contribuições pode elevar-se, ante o aumento da sinistralidade decorrente da mais intensa utilização dos serviços em consequência da idade dos beneficiários. Nesse ponto, assinalou que ${ }^{(29)}$

não se vê como, sem quebra do equilíbrio contratual preservado pela equação securitária, chegar à consequência de extraordinário aumento das prestações da seguradora sem elevação, também, do valor das contribuições, que, no caso, (...) realiza-se segundo

\footnotetext{
${ }^{25}$ SUPERIOR TRIBUNAL DE JUSTIÇA. Recurso Especial (REsp) 1.102.848/SP, cit.

${ }^{26}$ Id. Ibid.

${ }^{27}$ Ressalte-se, mais uma vez, que a legalidade da cláusula de rescisão contratual não foi objeto deste julgamento.

${ }^{28}$ SUPERIOR TRIBUNAL DE JUSTIÇA. Recurso Especial (REsp) 1.102.848/SP, cit.

${ }^{29}$ Id. Ibid.
} 
cláusula de redação precisa e equilibrada, em que não se detectam malícia, má-fé ou abuso.

Portanto, para Sidnei Beneti, a cláusula de rescisão do contrato por alta sinistralidade não é válida. Por outro lado, para ele, a cláusula de reajuste por sinistralidade é válida, visto que necessária à manutenção do equilíbrio contratual. Em suas razões, justificou a validade desta cláusula neste caso específico também no fato de que sua redação é precisa e equilibrada, não vislumbrando, portanto, malícia, má-fé ou abuso.

No mesmo julgado, Nancy Andrighi fez uma análise da cláusula de reajuste por sinistralidade considerando a natureza do contrato de seguro e explicou que:(30)

qualquer mecanismo que possibilite à operadora reposicionar os riscos por ela originalmente assumidos mediante aumento das mensalidades, conferir-lhe-á vantagem excessiva frente aos conveniados, violando, inclusive, os arts. 39 , V e 51 , IV, do CDC, além de descaracterizar a própria natureza do contrato firmado, que pressupõe a álea, ou seja, a possibilidade de prejuízo simultânea à de lucro. Na prática, é justamente o que induz a cláusula de revisão por aumento dos sinistros. A operadora reduz sensivelmente a contingência que o contrato lhe proporciona passando a controlar e minimizar seus riscos, mantendo o custo da operação em patamar que lhe convém, transferindo um ônus originalmente seu para a parte adversa. Além disso, a utilização de artifícios para redimensionar os riscos inerentes ao contrato possibilita às operadoras mascarar o preço real dos planos de saúde, oferecendo o serviço a custos iniciais baixos e atrativos, de forma a captar clientes, sabendo de antemão que, ao longo da execução do acordo, poderá unilateralmente reajustar as mensalidades de modo a reduzir os riscos assumidos, em detrimento dos conveniados, rompendo o binômio risco-mutualismo, próprio dos contratos de seguro.

Assim, para Nancy Andrighi, a cláusula de reajuste por sinistralidade é ilegal na medida em que permite alteração unilateral do contrato. A ministra vedou também a possibilidade de rescisão contratual. Explicou que:(31)

Os contratos cativos não são apenas de trato sucessivo. Eles surgem de uma relação de confiança que advém do convívio reiterado proporcionado pela continuidade do contrato, inculcando no consumidor a expectativa de conservação da qualidade do serviço e do equilíbrio econômico. Como envolve serviços essenciais, o consumidor busca segurança e estabilidade na contratação, não Ihe sendo interessante qualquer forma de rescisão, até porque, de regra, esses serviços são prestados apenas por um diminuto número de fornecedores, únicos que detém (sic) capacidade

\footnotetext{
${ }^{30}$ SUPERIOR TRIBUNAL DE JUSTIÇA. Recurso Especial (REsp) 1.102.848/SP, cit.

${ }^{31}$ Id. Ibid.
} 
financeira, conhecimento técnico e autorização estatal para tanto. Por tudo isso, a única alternativa aceitável para o consumidor é a manutenção dessa relação contratual, fazendo com que o princípio da conservação dos contratos adquira especial relevância em contratos dessa natureza, de sorte a dificultar que o fornecedor se liberte do vínculo contratual.

Logo, para Nancy Andrighi, também a cláusula de rescisão contratual é ilegal.

Por fim, Luis Felipe Salomão sustentou, no Al 1.328.171/SP, ${ }^{(32)}$ que há abusividade no reajuste, confirmando o entendimento do tribunal de origem, que justificou tal posição ao afirmar que a operadora nem ao menos apresentou planilhas de custo que justificassem um aumento de $400 \%$ em um ano. Salomão nada mencionou com relação à cláusula de rescisão, já que no referido processo a mesma não foi objeto de discussão.

De toda a descrição feita resulta que, com relação à cláusula de reajuste por sinistralidade, são duas as posições dos ministros sobre o tema. De um lado, há os que entendem que o contrato é empresarial, devendo ser aplicado o Código Civil com fundamento jurídico na liberdade de negociação entre as empresas contratantes e, por conseguinte, esse grupo conclui pela validade da cláusula de reajuste por sinistralidade. De outro, há os que entendem que se trata de contrato de adesão, de consumo e/ou cativo de longa duração, e/ou que envolve a saúde e que, por conseguinte, se deve aplicar o CDC, já que não há ampla liberdade de negociação que legitime e valide suas cláusulas. Foram invocados também tanto a falta de apresentação de documentos necessários que justifiquem o reajuste aplicado como o controle unilateral e indevido de custos pela operadora, argumentos que, na verdade, são duas faces da mesma moeda.

A questão da rescisão foi abordada de forma lacônica ou indireta por alguns ministros, já que não parece ter sido objeto específico desses recursos. Sidnei Beneti afirma que o contrato é cativo de longa duração, o que, na sua visão, impede a rescisão imotivada do contrato, mas não o reajuste por sinistralidade. Massami Uyeda menciona a liberdade do empregador que oferece pacote de benefícios aos seus empregados de procurar outra operadora para fornecer tal serviço quando quiser e, com base nesse argumento, entende que não há hipossuficiência nem aplicação do CDC ao caso. Infere-se, então, que Uyeda e os desembargadores convocados Vasco Della Giustina e Paulo Furtado (que acompanharam o voto de Uyeda) concluem pela liberdade de rescisão contratual por ambas as partes. Nancy Andrighi demonstrou ser contrária à rescisão contratual porque no seu entender trata-se de contrato cativo de longa duração e Luis Felipe Salomão não trata da rescisão de forma direta nem indireta, mas

\footnotetext{
${ }^{32} \mathrm{Ag}$ n. 1.328.171/SP. Agravo de Instrumento, Relator Ministro Luis Felipe Salomão, j. 25.5.2011, DJ. 6.6.2011, Documento 15672484 Despacho/decisão, p.1.
} 
conclui pela aplicação do CDC ao contrato, o que permite inferir que o mesmo não aceitaria a possibilidade de rescisão imotivada do contrato.

Nesse contexto, surge então o interesse de identificar os princípios constitucionais, que devem ser aplicados na interpretação de conflitos decorrentes desse reajuste e de eventual rescisão contratual decorrente da alta sinistralidade do contrato, analisando então a principiologia constitucional no tocante ao direito à saúde, à liberdade de contratar e à solidariedade.

\section{Principiologia constitucional: direito social à saúde, liberdade de contratar e solidariedade}

Em 1948, a Assembleia Geral da ONU adotou a Declaração Universal dos Direitos do Homem e, em 1966, aprovou dois pactos de direitos humanos: o Pacto de Direitos Civis e Políticos e o Pacto de Direitos Econômicos, Sociais e Culturais, que, entre outros direitos, passam a assegurar o direito de toda pessoa "ao desfrute do mais alto nível possível de saúde física e mental". (33)

O Comentário Geral $n^{\circ}$. 14(34) sobre direitos econômicos, sociais e culturais, publicado pelo Comitê da ONU em 11 de agosto de 2000, em Genebra, procura dar maior concretude aos direitos e obrigações decorrentes da implementação do "direito ao mais alto nível de saúde possível". O Comentário esclarece que este direito é de natureza individual, já que assegura o controle sobre a saúde e o corpo a cada indivíduo, como também de natureza pública e coletiva, à medida que assegura o direito de todos a um sistema de saúde igualitário, o qual deve ser direta ou indiretamente implementado pelo Estado, da melhor forma possível diante da limitação dos recursos materiais disponíveis, desde que se busque sempre, de forma progressiva e prioritária, o aperfeiçoamento desse sistema, considerando todas as determinantes sociais da saúde.

Vale dizer que, antes disso, em 1948, a Constituição da Organização Mundial da Saúde(35) já havia definido a saúde como um estado completo de bem-estar físico, mental e social. No texto atual, consta, inclusive, a responsabilização dos governos de cada país pela saúde dos seus povos (alterações no texto original foram incorporadas em 1977, 1984, 1994 e 2005).

Veja-se, portanto, que a evolução do direito e do conceito de saúde no plano nacional tanto influencia como vem sofrendo influências dos desdobramentos vividos por esse setor no plano internacional. Pode-se dizer que a área da saúde é especialmente sensível aos efeitos da globalização em diversos de seus

\footnotetext{
${ }^{33}$ UNITED NATIONS. International Covenant on Economic, Social and Cultural. Disponível em: <http://www2.ohchr.org/english/law/cescr.htm\#art12>. Acesso em: 15 fev. 2012.

${ }^{34}$ UNITED NATIONS. General Comment No 14 (2000). The right to the highest attainable standard of health: 11/08/2000. E/C. 12/2000/4. (General comments). Disponível em: <http://www.unhchr.ch/ tbs/doc.nsf/(symbol)/E.C.12.2000.4.En>. Acesso em: 15 fev. 2012.

${ }^{35}$ WHO. Basic Documents, 47th ed. 2009. p. 1.
} 
aspectos: ações judiciais internacionais baseadas no direito humano à saúde; estabelecimento de regras sobre condições sanitárias e ambientais que influenciam o comércio de produtos e vice-versa; estabelecimento de regulamentos, convenções e práticas sobre controle de doenças contagiosas, sobre controle de riscos de doenças não contagiosas como as causadas pelo fumo e pela obesidade e sobre a migração de médicos e enfermeiras entre países; políticas e regras sobre acesso a medicamentos e sobre propriedade intelectual e, ainda, estudos sobre o fortalecimento de sistemas nacionais de saúde.

Com relação ao último tema, cabe dizer que os países membros da Organização Mundial da Saúde (OMS), na Assembleia Geral de 2005, adotaram a Resolução $58.33,{ }^{(36)}$ reconhecendo a importância da implantação de sistemas de saúde universais, com equidade de acesso e de financiamento e com sistema de proteção contra os altos gastos financeiros. Por conseguinte, a OMS passou a reconhecer a importância desses elementos nas políticas de saúde defendidas pela organização, conforme se verifica do texto abaixo:

\begin{abstract}
Universal coverage is defined as access to key promotive, preventive, curative and rehabilitative health interventions for all at an affordable cost, thereby achieving equity in access. The principle of financial-risk protection ensures that the cost of care does not put people at risk of financial catastrophe. A related objective of health-financing policy is equity in financing: households contribute to the health system on the basis of ability to pay. Universal coverage is consistent with WHO's concepts of health for all and primary health care. ${ }^{(37)}$
\end{abstract}

Percebe-se sobre esse tema que a nossa Constituição encontra-se entre as mais avançadas do mundo, já que acolhe integralmente os valores e direitos previstos no pacto de direitos econômicos, sociais e culturais, como também é coerente com as orientações emanadas da OMS, reconhecendo direito universal à saúde em seus artigos 196 e seguintes. Veja-se que a dignidade da pessoa humana passou a ser o valor central e basilar do diploma constitucional de 1988, conforme artigo $1^{\circ}$, inciso III, da CF/88.

Fica evidente, portanto, que o direito à saúde não mais se circunscreve aos limites daqueles direitos garantistas, consagrados pelas revoluções burguesas e preocupados com uma racionalidade formal e com uma ética da responsabilidade. Ao contrário, verifica-se que o direito à saúde deve ser interpretado e entendido dentro de uma ética de convicção, na qual os fins e o conteúdo

\footnotetext{
${ }^{36}$ WHO. Resolução adotada na $58^{\mathrm{a}}$ Assembleia Mundial da Saúde. Disponível em: <http://www.who. int/providingforhealth/topics/WHA58_33-en.pdf>. Acesso em: 16 jan. 2013.

${ }^{37} \mathrm{WHO}$. Health Financing for Universal Coverage / Sustainable Health Financing, universal coverage and social health insurance / World Health Assembly Resolution 58.33(2005) / Universal Coverage. Disponível em: <http://www.who.int/health_financing/documents/cov-wharesolution5833/en/index. html>. Acesso em: 16 jan. 2013.
} 
é que devem atribuir legitimidade às normas. Conforme Tojal, (38) "Está, pois, o Estado juridicamente obrigado a exercer as ações e serviços de saúde visando à construção da nova ordem social, cujos objetivos, repita-se são o bem-estar e a justiça sociais, pois a Constituição lhe dirige impositivamente essa tarefa". Nesse sentido, "o direito passa então a assumir o papel de fator implementador das transformações sociais, veiculando inclusive prestações públicas". ${ }^{39)}$ Por conseguinte,

\begin{abstract}
a saúde depende, ao mesmo tempo, de características individuais, físicas e psicológicas, mas, também, do ambiente social e econômico, tanto daquele mais próximo das pessoas, quanto daquele que condiciona a vida dos Estados. O que obriga afirmar que, sob a ótica jurídica, a saúde deverá inevitavelmente implicar aspectos individuais, sociais e de desenvolvimento. ${ }^{(40)}$
\end{abstract}

Dallari explica ainda que "é impensável que se conceba saúde sem uma dimensão coletiva, que envolva a comunidade e o Estado, que por meio de ações variadas, intervém não só em atividades prestacionais, como também no controle sanitário e de zoonoses".(41)

Para entender corretamente os aspectos individuais, sociais e de desenvolvimento do direito à saúde, no Brasil, é indispensável abordar os fundamentos constitucionais que concedem a este direito o papel de fator implementador de transformações sociais.

O artigo 194 da CF/88 elenca os princípios aplicados à seguridade social, ou seja, à previdência, à saúde e à assistência social, abrangendo: I - universalidade da cobertura e do atendimento; II - uniformidade e equivalência dos benefícios e serviços às populações urbanas e rurais; III - seletividade e distributividade na prestação dos benefícios e serviços; IV - irredutibilidade do valor dos benefícios; $\mathrm{V}$ - equidade na forma de participação no custeio; VI - diversidade da base de financiamento; e VII - caráter democrático e descentralizado da administração, mediante gestão quadripartite, com participação dos trabalhadores, dos empregadores, dos aposentados e do Governo nos órgãos colegiados (Redação dada pela Emenda Constitucional $\mathrm{n}^{\circ} 20$, de 1998).

Já os artigos 196, 197 e 199 da CF/88, respectivamente, cuidam dos deveres do Estado, da relevância pública das ações de saúde e da autorização à prestação da assistência à saúde à iniciativa privada.

\footnotetext{
${ }^{38}$ TOJAL, Sebastião Botto de Barros. A Constituição Dirigente e o direito regulatório do estado social: o direito sanitário. In: ARANHA, Márcio lorio (Org.). Direito sanitário e saúde pública. Brasília-DF: Ministério da Saúde, Secretaria de Gestão do Trabalho e da Educação na Saúde, Departamento de Gestão da Educação na Saúde, 2003. v. 1, p. 28.

${ }^{39}$ Id., loc. cit.

${ }^{40}$ DALLARI, Sueli; NUNES JUNIOR, Vidal Serrano. Direito sanitário. São Paulo: Ed. Verbatim, 2010. p. 11.

${ }^{41}$ Id. Ibid., p. 12.
}

R. Dir. sanit., São Paulo, v. 14, n. 2, p. 88-112, jul./out. 2013 
A análise da professora Sueli Dallari e dos autores por ela citados sobre o direito fundamental à saúde na ordem constitucional é percuciente. Interessa-nos, diretamente, a parte que trata da responsabilidade do Estado e dos entes privados autorizados a prestar serviços de saúde:

(...) a responsabilidade estatal, em relação à saúde, não se limita à prestação de serviços públicos, mas também à sua regulamentação, fiscalização e controle, nos termos do art.197 da Lei Maior, que qualifica as ações e serviços de saúde como de relevância pública, quer quando prestados diretamente, quer quando executados por terceiros ou por pessoa física ou jurídica de direito privado. Elucidativas, nesse sentido, as conclusões alcançadas por Antonio Augusto Mello de Camargo Ferraz e Antonio Herman de Vasconcellos e Benjamin:

"Quando a Constituição Federal afirma que 'a saúde é direito de todos e dever do Estado' (art.196), sendo de 'relevância pública as ações e serviços de saúde, cabendo ao Poder Público dispor, nos termos da lei, sobre sua regulamentação, fiscalização e controle' (art.197) e que 'a assistência à saúde é livre a iniciativa privada' (art.199, caput), diversas conclusões daí podem ser tiradas:

a. a saúde é direito público subjetivo exigível contra o Estado e contra todos os que, mesmo que entes privados, sob a chancela deste a garantam;

b. a saúde é sempre assegurada através da atuação de uma função pública estatal, mesmo quando prestada por particulares, sendo que apenas as suas 'ações e serviços' não têm exercício exclusivo do Estado; por isso mesmo, são consideradas de relevância pública;

c. como função pública estatal, cabe ao Estado a direção da prestação de serviços e ações de saúde, devendo fixar as diretrizes e parâmetros para o exercício destes; com isso, pode-se dizer que é limitada a liberdade dos prestadores de serviços privados;

d. as desconformidades nos serviços e ações permitem que o Estado exerça todo seu múnus, inclusive com a utilização do instituto da desapropriação;

e. como direito público subjetivo, a saúde cria uma série de interesses na sua materialização, interesses esses que ora são tipicamente públicos, ora difusos, ora coletivos, individuais homogêneos ou individuais simples;

f. tais interesses, quando contrariados, dão legitimidade a uma série de sujeitos, públicos e privados, para buscarem, judicialmente sua proteção (para tanto pode-se utilizar, além de outros estatutos, a Lei 7347/85 e o Código de Defesa do Consumidor). ${ }^{(42)}$

${ }^{42}$ DALLARI, Sueli; NUNES JUNIOR, Vidal Serrano. op. cit., p. 70-71. 
Portanto, cabe à iniciativa privada a faculdade de decidir se quer ou não atuar na prestação de serviços de saúde, diversamente do setor público, que é obrigado a atuar neste setor. Entretanto, uma vez que o representante da iniciativa privada toma a decisão de inserir-se no setor de saúde, passa imediatamente a assumir todas as obrigações decorrentes do direito fundamental à vida e à saúde, perante aqueles por quem se responsabiliza.

De fato, o sistema de saúde suplementar é, assim como o público, regido pelos princípios inscritos nos artigos 194 a 199 da CF/88, o que significa que ambos os sistemas devem pautar ações conjuntas com o fim de garantir a universalidade da cobertura e do atendimento, a integralidade dos serviços de saúde e a equidade de financiamento e de acesso aos serviços de saúde. São esses os valores que devem estar no centro das políticas e dos julgamentos que orientam ambos os sistemas, que, aliás, devem cada vez mais buscar atuar em cooperação, quiçá, até, em complementação. Nessa condição, tais valores atuam como vetores diretivos e interpretativos das ações e questões relacionadas ao direito à saúde.

É a atuação de tais valores como vetores diretivos do sistema privado de saúde que explica o papel do Estado nesse campo. Atualmente, a atuação do Estado sobre o sistema de saúde suplementar ocorre através da Agência Nacional de Saúde Suplementar (ANS), com base nas Leis $n^{\circ s} 9.656 / 98^{(43)}$ e $9.961 / 00 .{ }^{(44)}$ Nos termos do artigo $3^{\circ}$ da Lei $n^{\circ} 9.961 / 00$ : "A ANS terá por finalidade institucional promover a defesa do interesse público na assistência suplementar à saúde, regulando as operadoras setoriais, inclusive quanto às suas relações com prestadores e consumidores, contribuindo para o desenvolvimento das ações de saúde no país". O artigo $4^{\circ}$ do mesmo diploma legal, em seus 42 incisos, atribui competências específicas à Agência.

Portanto, a primeira constatação que se faz é a de que a ANS não cumpre seu papel constitucional, pois, como visto, deixa de regular, de forma adequada, os reajustes e a rescisão do contrato coletivo empresarial de assistência à saúde que hoje representa os interesses de $62 \%{ }^{(45)}$ das pessoas que possuem contrato de assistência de saúde. Deixa, portanto, de exercer sua função constitucional, qual seja, a de fixar as necessárias diretrizes para que o setor de saúde suplementar seja pautado pela equidade de financiamento e de acesso aos serviços de saúde.

É verdade que o parágrafo $2^{\circ}$ do artigo $35-E$ da Lei $n^{\circ} 9.656 / 98^{(46)}$ confere expressamente, à ANS, quanto aos contratos individuais, competência para aprovar

\footnotetext{
${ }^{43}$ BRASIL. Lei $n^{\circ} 9.656$, de 3 de junho de 1998, cit.

${ }^{44}$ BRASIL. Lei no 9.961, de 28 de janeiro de 2000. "Cria a Agência Nacional de Saúde Suplementar - ANS e dá outras providências". Disponível em: <http://www.planalto.gov.br/ccivil_03/leis/L9961. htm>. Acesso em: 19 ago. 2013.

${ }^{45}$ Conforme dados indicados.

${ }^{46}$ Art. 35-E. "A partir de 5 de junho de 1998, fica estabelecido para os contratos celebrados anteriormente à data de vigência desta Lei que: (...) § $2^{\circ}$ Nos contratos individuais de produtos de
} 
previamente a aplicação das cláusulas de reajuste contratual. Alguns entendem, ${ }^{(47)}$ portanto, que a ANS não teria tal competência quanto aos contratos coletivos. De qualquer forma, como dito, a ANS editou a $\mathrm{RN} \mathrm{n}^{\circ} 309,{ }^{(48)}$ pela qual determinou o agrupamento de contratos coletivos empresariais e por adesão, firmados após $1^{\circ}$ de janeiro de 1999, ou adaptados à Lei n $9.656 / 98$, para fins de cálculo e aplicação de reajuste, com o fim, justamente, de diluir o risco de contratos coletivos com 30 ou menos beneficiários em um grupo maior de beneficiários.

Apesar do tardio, mas inegável, avanço, contratos empresariais que tenham 31 beneficiários ou mais continuarão expostos a um risco altíssimo. E mesmo os contratos protegidos pela $\mathrm{RN} \mathrm{n}^{\circ} 309$ devem possibilitar a seus beneficiários alguma forma de conferência ou controle sobre o cálculo e sobre a aplicação de tais reajustes, seja de forma direta pelas próprias partes envolvidas no contrato, seja através da ANS.

Não há dúvida de que o legislador teve como prioridade proteger os consumidores que contratam individualmente; daí a preocupação em assegurar, expressamente no parágrafo $2^{\circ}$ do artigo $35-E$ da Lei $n^{\circ} 9.656 / 98$, o controle direto da aplicação dos reajustes dos contratos individuais pela ANS. Isso não quer dizer, entretanto, que os beneficiários de contratos empresariais devam continuar desprotegidos. É preciso analisar a legislação em seu conjunto.

A prestação de serviços de saúde, alçada pelo diploma constitucional à categoria de atividade de relevância pública, ${ }^{(49)}$ requer a aplicação, em qualquer instância decisória, dos princípios constitucionais a ela relacionados, e, no caso ora em comento, especialmente do princípio da equidade de financiamento e de acesso aos serviços de saúde. Tais princípios devem se sobrepor aos demais, mesmo que ainda não tenham sido objeto de uma política pública específica para esses contratos. Isso quer dizer que os reajustes devem ser aplicados com base na mais larga escala de segurados da operadora e não apenas com base no número de funcionários de uma única empresa, considerando desigualmente os

que tratam o inciso I e o $\S 1^{\circ}$ do art. 1을 desta Lei, independentemente da data de sua celebração, a aplicação de cláusula de reajuste das contraprestações pecuniárias dependerá de prévia aprovação da ANS". BRASIL. Lei n 9.656, de 3 de junho de 1998, cit.

${ }^{47}$ É o que se depreende do comentário de Maria Stella Gregori: "Os reajustes somente podem ocorrer após o decurso de, no mínimo, um ano, contado da data de assinatura do contrato. Todos os ajustes de planos individuais e de planos coletivos operados por autogestões não patrocinadas, cujo financiamento é feito exclusivamente pelos beneficiários, devem ser analisados e aprovados previamente pela ANS. Os reajustes dos demais planos coletivos deverão ser informados à Agência”. GREGORI, Maria Stella. Planos de saúde: a ótica da proteção do consumidor. São Paulo: Instituto Brasileiro de Política e Direito do Consumidor; Ed. Revista dos Tribunais, 2007. p.156.

${ }^{48}$ BRASIL. AGÊNCIA NACIONAL DE SAÚDE SUPLEMENTAR. Resolução Normativa - RN n 309, cit.

${ }^{49}$ Sobre o conceito de relevância pública na CF/88 ver: GRAU, Eros Roberto. O conceito de relevância pública na Constituição de 1988. Revista de Direito Sanitário, São Paulo, v. 5, n. 2, p. 68-76, jul. 2004 e FERRAZ, Antônio Augusto Mello de Camargo; BENJAMIN, Antônio Herman de Vasconcelos. O conceito de "relevância pública" na Constituição de 1988. Revista de Direito Sanitário, São Paulo, v. 5, n. 2, p. 77-89, jul. 2004. 
desiguais, a fim de proporcionar o mais amplo acesso aos serviços de saúde a todos os possíveis beneficiários dos contratos privados.

Ocorre que não é isso o que temos observado em alguns julgados do país, conforme demonstrado. As decisões judiciais ali identificadas procuram apenas definir esse contrato dentro de um dos ramos do direito privado que a ele se relacionam.

Considerando que esse contrato enseja uma relação triangular: 1 - operadora de saúde $\mathrm{x}$ beneficiário/empregado; 2 - beneficiário/empregado x empresa estipulante/empregadora; e 3 - empresa Estipulante/Empregadora x operadora de saúde, verifica-se o surgimento de diferentes interpretações jurídicas, baseadas nos diferentes diplomas legais que regem a relação específica de cada um dos lados do triângulo: CDC quando se prioriza a relação operadora x beneficiário/ empregado; Consolidação das Leis Trabalhistas ${ }^{(50)}$ quando se prioriza a relação beneficiário/empregado x empresa estipulante/empregadora; e Código Civil de $2002(C C / 2002),{ }^{(51)}$ quando se prioriza a relação operadora de saúde x empresa estipulante/ empregadora.

No tocante à interpretação dos conflitos oriundos do reajuste por sinistralidade e rescisões contratuais dele decorrentes, as decisões judiciais identificadas divergem principalmente quanto à aplicação do CDC ou do CC/2002. Os princípios constitucionais que regem o direito à saúde e/ou a ausência de uma política da ANS que os ampare poucas vezes são mencionados pelos decisórios, o que configura flagrante violação às normas constitucionais.

No entanto, quaisquer que sejam as discussões jurídicas sobre planos de saúde, devem elas se pautar primordialmente pelos princípios constitucionais que tratam do direito à saúde de forma ampla, sob pena de reduzir a saúde a um produto mercantil qualquer.

De qualquer forma, diante da insuficiência da regulação da ANS e da ausência da aplicação do direito constitucional à saúde aos conflitos judiciais ora em comento, cabem algumas palavras sobre as questões de direito privado discutidas atualmente nos tribunais do país que tratam dos conflitos sobre reajustes em contratos empresariais de saúde.

Primeiramente, mesmo que por suposição esse contrato não envolvesse saúde ou nenhum outro serviço de relevância pública, não há dúvida de que, no mínimo, o CDC deveria ser aplicado a tais conflitos, haja vista seu impacto direto nos interesses dos beneficiários do seguro, seja porque em boa parte dos casos são os próprios beneficiários que efetuam o pagamento de ao menos parte do valor do prêmio, seja porque reajustes significativos ou consecutivos podem levar até a uma rescisão

\footnotetext{
${ }^{50}$ BRASIL. Decreto-Lei $n^{\circ} 5.452$, de $1^{\circ}$ de maio de 1943. "Aprova a Consolidação das Leis do Trabalho". Disponível em: < http://www.planalto.gov.br/ccivil_03/decreto-lei/Del5452compilado. htm>. Acesso em: 19 ago. 2013.

${ }^{51}$ BRASIL. Lei $\mathrm{n}^{\circ} 10.406$, de 10 de janeiro de 2002. "Institui o Código Civil". Disponível em: <http:// www.planalto.gov.br/ccivil_03/leis/2002/10406.htm>. Acesso em: 19 ago. 2013.
} 
contratual do referido contrato, em prejuízo dos beneficiários. E a leitura do artigo $2^{\circ}$ do CDC não deixa dúvidas quanto à sua aplicação aos conflitos ora analisados. ${ }^{(52)}$

Imagine-se, porém, que outro contrato com esse mesmo tipo de reajuste fosse celebrado entre uma operadora de seguro e uma empresa, sendo esta última também a sua única beneficiária. Teríamos então uma relação tipicamente empresarial, que ensejaria a aplicabilidade do CC/2002. Ainda assim, qualquer interpretação quanto aos reajustes por sinistralidade deveria estar atenta aos princípios dos artigos $1^{\circ}$ e 170 da CF/88 e do próprio CC/2002, que conformam o princípio da livre iniciativa ao princípio da solidariedade, exigindo o cumprimento de princípios como o da função social do contrato e o da boa-fé objetiva para que se obtenha um efetivo equilíbrio contratual. ${ }^{(53)}$

Portanto, mesmo na hipótese de aplicação exclusiva do CC/2002, a validade de cláusulas de reajuste e de rescisão, em contratos empresariais, depende da constatação de que tais regras e o contrato como um todo estão a serviço da pessoa, sua dignidade e desenvolvimento, o que, em poucas palavras, obriga que no mínimo seja verificado, no caso concreto, o preenchimento dos deveres de informação, de prestação de contas, de colaboração e de cooperação, prestigiados pelo Código Civil de 2002.

\section{Considerações Finais}

O sistema de saúde suplementar é, assim como o público, regido pelos princípios inscritos nos artigos 194 a 199 da CF/88, o que significa que ambos devem pautar suas ações de forma conjunta, visando à universalidade da cobertura e do atendimento, à integralidade dos serviços de saúde e à equidade de financiamento e de acesso aos serviços de saúde. São esses os valores que devem estar no centro das políticas e dos julgamentos que orientam ambos os

\footnotetext{
${ }^{52}$ Art. $2^{\circ}$. "Consumidor é toda pessoa física ou jurídica que adquire ou utiliza produto ou serviço como destinatário final. Parágrafo único. Equipara-se a consumidor a coletividade de pessoas, ainda que indetermináveis, que haja intervindo nas relações de consumo". BRASIL. Lei $n^{\circ} 8.078$, de 11 de setembro de 1990, cit.

${ }^{53}$ De acordo com Teresa Negreiros, "A leitura do direito civil sob a ótica constitucional atribui novos fundamentos e, consequentemente, novos contornos à liberdade contratual. Em meio ao processo de despatrimonialização ou de funcionalização do direito civil, a noção de autonomia da vontade sofre profundas modificações no âmbito do contrato, sintetizadas na afirmação de que a autonomia negocial, diferentemente das liberdades existenciais, não constitui em si mesma um valor. Ao contrário, a livre determinação do conteúdo do regulamento contratual encontra-se condicionada à observância das regras e dos princípios constitucionais, o que significa, no quadro de valores apresentado pela Constituição brasileira, conceber o contrato como um instrumento a serviço da pessoa, sua dignidade e desenvolvimento. Assim, pela via da constitucionalização, passam a fazer parte do horizonte contratual noções e ideais como justiça social, solidariedade, erradicação da pobreza, proteção ao consumidor, a indicar, enfim, que o direito dos contratos não está à parte do projeto social articulado pela ordem jurídica em vigor no país". NEGREIROS, Teresa. Teoria do contrato: novos paradigmas. 2. ed. Rio de Janeiro: Renovar, 2006. p. 106.
} 
sistemas, que, aliás, devem cada vez mais buscar atuar em cooperação, quiçá, até, em complementação.

Dessa forma, cabe à ANS regular os planos empresariais de saúde no tocante aos seus reajustes e rescisão, com base nos princípios constitucionais do direito à saúde, dada a relevância pública de seu objeto.

De qualquer forma, ainda que a ANS tenha regulamentado o tema de forma insuficiente, os princípios constitucionais que regem o direito à saúde e, nesse caso, em especial, o princípio da equidade de financiamento e de acesso à saúde devem ser aplicados com prioridade na interpretação dos conflitos judiciais dos temas ora examinados.

No âmbito do direito privado, não há dúvidas de que os temas ora discutidos devem ser interpretados à luz do CDC. O que não é mais admitido, nem mesmo em típicos contratos empresariais, é a interpretação que superestima a autonomia da vontade como valor isolado, sem considerar os princípios constitucionais previstos no art. $1^{\circ}$ e 170 da CF/88 e no próprio CC/2002, tais como a boa-fé objetiva, a função social e o equilíbrio contratual. ${ }^{(54)}$

Espera-se que o apontamento dessas questões possa contribuir para uma reflexão sobre o tema.

\section{Referências}

ANS. Disponível em: <http://www.ans.gov.br/index.php/materiais-para-pesquisas/ perfil-do-setor/dados-e-indicadores-do-setor>. Acesso em: 23 dez. 2011.

BAHIA, Ligia. A unificação do sistema público e a expansão do segmento suplementar: as contradições entre o SUS universal e as transferências de recursos públicos para os planos e seguros privados de saúde. Ciência \& Saúde Coletiva, Rio de Janeiro, v. 13, n. 5, p. 1398-1408, set./out. 2008.

COHN, Amélia; NUNES, Edison; JACOBI, Pedro R; KARSCH, Ursula S. A saúde como direito e como serviço. 6. ed. São Paulo: Cortez, 2010.

DALLARI, Sueli. Direito sanitário. In: ARANHA, Márcio lorio (Org.). Direito sanitário e saúde pública. Brasília-DF: Ministério da Saúde, Secretaria de Gestão do Trabalho e da Educação na Saúde, Departamento de Gestão da Educação na Saúde, 2003. v. 1. Disponível em: <http://bvsms.saude.gov.br/bvs/publicacoes/ direito_sanitarioVol1.pdf>. Acesso em: 15 fev. 2012.

DALLARI, Sueli; NUNES JUNIOR, Vidal Serrano. Direito sanitário. São Paulo: Ed. Verbatim, 2010.

\footnotetext{
${ }^{54}$ Alguns dispositivos do CC/2002 que tratam do tema: artigos 113, 187, 421,422. 478, 479 e 480.
} 
FERRAZ, Antônio Augusto Mello de Camargo; BENJAMIN, Antônio Herman de Vasconcelos. O conceito de "relevância pública" na Constituição de 1988. Revista de Direito Sanitário, São Paulo, v. 5, n. 2, p. 77-89, jul. 2004.

GRAU, Eros Roberto. O conceito de relevância pública na Constituição de 1988. Revista de Direito Sanitário, São Paulo, v. 5, n. 2, p. 68-76, jul. 2004.

GREGORI, Maria Stella. Planos de saúde: a ótica da proteção do consumidor. São Paulo: Instituto Brasileiro de Política e Direito do Consumidor; Ed. Revista dos Tribunais, 2007.

MARQUES, Cláudia Lima et al. Saúde e responsabilidade 2: a nova assistência privada à saúde, São Paulo: Ed. Revista dos Tribunais, 2008. (Biblioteca de direito do consumidor; v.36).

MENDES, Áquilas; MARQUES, Rosa Maria. Crônica de uma crise anunciada: o Financiamento do SUS sob a dominância do capital financeiro. Disponível em: <http://www.apufpr.org.br/artigos/trabalho_cronica_de_uma_crise_anunciada_ financiamento_sus_aquilas_mendes_e.pdf>. Acesso em: 22 maio 2012.

MENICUCCI, Telma Maria Gonçalves, Relação público-privada no sistema de saúde brasileiro: opacidade cognitiva e analítica. Ciência \& Saúde Coletiva, Rio de Janeiro, v. 13, n. 5, p. 1400-1403, set./out. 2008.

NEGREIROS, Teresa. Teoria do contrato: novos paradigmas. 2. ed. Rio de Janeiro: Renovar, 2006.

OCKÉ-REIS, Carlos Octávio. O mercado de planos de saúde: o problema vira solução. Ciência \& Saúde Coletiva, Rio de Janeiro, v. 13, n. 5, p. 1398-1400, set./out. 2008.

PAIM, Jairnilson Silva. Reforma sanitária brasileira: contribuição para compreensão e crítica. Salvador: Edufba; Rio de Janeiro: Ed. Fiocruz, 2008.

PLANOS de Saúde: nove anos após a Lei 9.656/98. As falhas da regulamentação, A omissão da Agência Nacional de Saúde (ANS), O comportamento do mercado. São Paulo: Conselho Regional de Medicina do Estado de São Paulo; Instituto de Defesa do Consumidor, 2007.

SILVA, Silvio Fernades da, Interfaces entre a Gestão do SUS e a regulação de planos privados de saúde. Ciência \& Saúde Coletiva, Rio de Janeiro, v. 13, n. 5, p. 1400-1403, set./out. 2008.

TEIXEIRA, Tarcísio. Cancelamento de Contrato de seguro sob alegação de aumento sazonal da sinistralidade - abusividade - aplicação do Código de Defesa do Consumidor. Revista de Direito Mercantil, Industrial, Econômico e Financeiro, São Paulo, n. 139, jul./set. 2005. 
TOJAL, Sebastião Botto de Barros. A Constituição Dirigente e o direito regulatório do estado social: o direito sanitário. In: ARANHA, Márcio lorio (Org.). Direito sanitário e saúde pública. Brasília-DF: Ministério da Saúde, Secretaria de Gestão do Trabalho e da Educação na Saúde, Departamento de Gestão da Educação na Saúde, 2003. v. 1.

UNITED NATIONS. General Comment No 14 (2000). The right to the highest attainable standard of health: 11/08/2000. E/C. 12/2000/4. (General comments). Disponível em: <http://www.unhchr.ch/tbs/doc.nsf/(symbol)/E.C.12.2000.4.En>. Acesso em: 15 fev. 2012.

International Covenant on Economic, Social and Cultural. Disponível em: <http://www2.ohchr.org/english/law/cescr.htm\#art12>. Acesso em: 15 fev. 2012. WHO. Basic Documents, 47th ed. 2009.

WHO. Health Financing for Universal Coverage / Sustainable Health Financing, universal coverage and social health insurance / World Health Assembly Resolution 58.33(2005) / Universal Coverage. Disponível em: <http://www.who. int/health_financing/documents/cov-wharesolution5833/en/index.html>. Acesso em: 16 jan. 2013.

WHO. Resolução adotada na $58^{a}$ Assembleia Mundial da Saúde. Disponível em: <http://www.who.int/providingforhealth/topics/WHA58_33-en.pdf>. Acesso em: 16 jan. 2013. 